\title{
A Interação entre pares: que lugar na avaliação do desempenho docente?
}

\author{
Susana Oliveira Sá
}

\begin{abstract}
Resumo
A avaliação do desempenho docente, quando realizada segundo o modelo da supervisão entre pares, tem assumido uma importância desmedida nas preocupações e nas atividades dos docentes, gerando tensões no ambiente profissional, para além das inerentes a qualquer dispositivo de avaliação e desvios em relação aos objetivos centrais propostos. Com este estudo, investigou-se de que forma a interação entre pares substitui com vantagem a supervisão entre pares, sobretudo em escolas onde os quadros docentes são estáveis e os seus docentes possuem mais de 15 anos de serviço. Neste contexto, optamos por uma investigação de natureza qualitativa, de tipo estudo de caso, recorrendo, para isso, à análise de narrativas de docentes e de entrevistas semiestruturadas às docentes. Os dados recolhidos foram tratados recorrendo às técnicas de análise de conteúdo, através do software de análise qualitativa webQDA. Em contextos similares, a interação entre pares constitui um indutor da melhoria da prática docente, uma vez que proporciona a hétero e a auto-reflexão. Este método contribui para a edificação de práticas de ensino reflexivas, e, consequentemente, para uma melhoria das aprendizagens, para o sucesso dos estudantes e para o desenvolvimento profissional dos docentes, sendo uma excelente alternativa à avaliação de desempenho docente.
\end{abstract}

Palavras-chave:

interação entre pares; sucesso na aprendizagem; desenvolvimento profissional; avaliação do desempenho docente. 


\section{L'interaction entre pairs: quelle est sa place dans l'évaluation de la performance des enseignants?}

Résumé: L'évaluation de l'enseignement performance, lorsqu'elle est effectuée sur le modèle de supervision par les pairs, a pris une importance disproportionnée dans les préoccupations et activités des enseignants, de créer des tensions dans le lieu de travail, en plus inhérent à tout dispositif d'évaluation et de déviation par rapport aux objectifs plantes proposées. Cette étude a examiné comment l'interaction entre pairs remplace avantageusement supervision par les pairs, en particulier dans les écoles où les enseignants sont stables et leurs enseignants ont plus de 15 ans de service. Dans ce contexte, nous avons choisi une recherche qualitative, type de cas d'étude, en utilisant pour cela, l'analyse des récits des enseignants et des entrevues semi-structurées avec les enseignants. Les données recueillies ont été analysées en utilisant les techniques d'analyse de contenu, à travers webQDA logiciel d'analyse qualitative. Dans des contextes similaires, l'interaction entre pairs est un inducteur de l'amélioration de la pratique de l'enseignement, car elle fournit une auto-réflexion et droite. Cette méthode contribue à l'édification des pratiques d'enseignement de réflexion, et donc à une amélioration de l'apprentissage pour la réussite des élèves et le développement professionnel des enseignants est une excellente alternative à l'évaluation de la performance des enseignants.

Mots-clés: interaction entre pairs; le succès dans l'apprentissage; perfectionnement professionnel; évaluation de la performance des enseignants.

\section{The peers interaction: that in Teacher Performance Assessment?}

Abstract: The teaching assessment of performance, in particular the peer supervision, became an inordinate importance among teachers, resulting in professional environment tensions inherent in any assessment device. This study investigates how the peers interaction replaces with advantage the peer supervision, particularly in schools where teaching staff are stable and their teachers have more than 15 years of service. In this context, we chose a qualitative research, like case study type, using for this the analysis of teachers' narratives and semi-structured interviews with teachers. The data collected were treated with content analysis methodology through webQDA qualitative analysis software. In similar contexts, peers' interaction is an inducer of improving teaching practices, since it enhances individual capacities, through self-reflection and reflection on other people's teaching skills. This method contributes to the building up of reflexive teaching practices, and consequently, to an improvement of learning, also in students' success, and the teachers' professional development, it is an excellent alternative to teacher performance assessment.

Keywords: peers interaction; success in learning; professional development; teacher performance assessment.

\section{La interacción entre pares: la utilizada en la evaluación de desempeño de los docentes?}

Resumen: La evaluación del desempeño docente, en particular, la supervisión de pares, se convirtió en una importancia desmesurada entre los docentes, lo que resulta en tensiones entorno profesional inherentes a cualquier dispositivo de evaluación. Este estudio investigó cómo la interacción entre pares sustituye ventajosamente entre la supervisión entre pares, especialmente en las escuelas donde los profesores son estables y sus profesores tienen más de 15 años de servicio. En este contexto, se optó por una investigación cualitativa, tipo estudio de caso, utilizando para ello, el análisis de las narrativas de los profesores y entrevistas semiestructuradas con profesores. Los datos recogidos fueron analizados utilizando las técnicas de análisis de contenido, a través de un software de análisis cualitativo webQDA. En contextos similares, la interacción entre pares es un inductor de la mejora de la práctica docente, ya que proporciona una auto-reflexión y recto. Este método contribuye a la consolidación de las prácticas de la enseñanza reflexiva, y por lo tanto a una mejora del aprendizaje para el éxito de los estudiantes y el desarrollo profesional de los docentes es una excelente alternativa a la evaluación de desempeño docente.

Palabras clave: interacción entre pares; el éxito en el aprendizaje; desarrollo profesional; evaluación de desempeño docente. 


\section{Introdução}

Este artigo resulta de uma investigação qualitativa, apresentada em comunicação no $5^{\circ}$ Congresso Ibero-Americano em Investigação Qualitativa (CIAIQ 2016), na Universidade Lusófona, na cidade do Porto, em Portugal, entre os dias 12 e 14 de julho de 2016.

A literatura, em geral, e a legislação da tutela, preconiza que a supervisão pedagógica associada aos modelos de formação e de desenvolvimento profissional dos docentes visa melhorar o ensino e a aprendizagem dos estudantes. A concretização mais eficaz destes propósitos, no entanto, parece associada fortemente à atividade quotidiana reflexiva, colaborativa e dotada de feedback atempado. Com a interação entre pares, a regulação proativa parece contribuir mais decididamente para a melhoria do desempenho de cada docente envolvido.

Este estudo pretende investigar se a interação entre pares será uma alternativa para a avaliação do desempenho docente, sobretudo em escolas com estabilidade docente e cujos docentes têm mais de 15 anos de serviço, e se a melhoria do ensino e da aprendizagem pode ser concretizada com vantagem sob esta forma dialógica, inserida no quotidiano da escola.

Em Portugal, o Decreto Regulamentar no 26/2012, Artigo 3, 1 e 2, estabelece que a avaliação de desempenho docente visa melhorar o ensino, a aprendizagem e a valorização profissional dos docentes, diagnosticando as suas necessidades, que serão integradas no plano de formação das escolas. E também determina, no Artigo $18^{\circ}, 3$ e 4, que aquela será realizada através da observação de 180 minutos de aulas, por observadores externos.

Ora, conjugando os meios propostos para o processo de avaliação com os objetivos pretendidos, conclui-se que aqueles não são adequados. Com efeito, mesmo no contexto de supervisão pedagógica, a observação não deve restringir-se à sala de aula, porque pressupõe a colaboração entre supervisor e docente supervisionado, e deve abarcar as situações diversas que compõem o todo da ação docente, para que este seja capaz, com o apoio adequado, de observar e agir, refletindo sobre o trabalho que desenvolve, sobre os efeitos da sua ação na aprendizagem dos alunos e o funcionamento da organização escolar. Todavia, a observação de aulas nos moldes propostos pela tutela, desprovida de acompanhamento e feedback do processo, apenas com o registo numa grelha de resultados observados durante 180 minutos, consistirá numa prática desvirtuada da supervisão pedagógica, não enquadrada na reflexividade inerente ao desenvolvimento profissional e incapaz de para ele contribuir. Portanto, a mera observação de 180 minutos de aula não permite concretizar aqueles objetivos da avaliação do desempenho docente. 


\section{Supervisão Pedagógica}

$\mathrm{Na}$ literatura, descreve-se a observação como um olhar disciplinado, delimitado e dirigido por objetivos: "a observação é um processo cuja função primeira, imediata, consiste em recolher informações sobre o objecto tomado em consideração, em função do objectivo organizador." (Damas \& De Ketele, 1985, p. 11).

Reforçando este ponto de vista, segundo Trindade (2007, p. 40),

é ainda através da Observação que podemos fornecer aos indivíduos observados a informação necessária para eliminarem ou diminuírem as discrepâncias entre o que pensam que fazem e o que realmente fazem. Tal contributo vai permitir-Ihes crescer em termos profissionais, ajustando os seus desempenhos àquilo que deles é esperado.

Se a observação acarreta pressupostos e subjectividade, será necessária?

Defende-se que esta observação controlada é integrante da prática de supervisão (Ribeiro, 2012), e para Trindade (2007, p.14), "a Observação, a Orientação vão estar ao serviço da Supervisão, sendo dela instrumentos privilegiados e nela encontrando os seus limites".

Apesar de diferentes, as teorias e os modelos de Supervisão Pedagógica asseveram a relevância da observação de aulas na construção e desenvolvimento do professor, considerando o docente enquanto pessoa e profissional.

Segundo Ribeiro (2012, p. 62), a validade desta técnica depende da precisão e do rigor das observações, as quais "deverão ser controladas e sistemáticas", e "ser planeada cuidadosamente, determinando "o quê" e "o como" observar".

Porém, mesmo controlada, esta técnica apresenta limitações, porque desvaloriza o contexto cultural, histórico e social dos sujeitos envolvidos na comunidade escolar concreta, a interação e a participação dos docentes, a possibilidade de mudanças no desempenho em resultado da confiança mútua entre pares e da avaliação formativa do desempenho (Alarcão \& Roldão, 2008).

\section{Interação entre Pares}

Avaliar supõe confrontar os efeitos das práticas com os resultados esperados, "interrogar-se sobre os processos que conduziram a tais efeitos, pôr eventualmente em questão os efeitos esperados" (Alves \& Machado, 2010, p. 25), sob uma perspetiva de prática reflexiva, como defendem vários autores (Atlet, Paquay \& Perrenoud, 2002). A maioria defende que as escolas devem fomentar a formação contínua dos docentes, 
partindo da reflexão e análise das suas próprias práticas, numa atmosfera de aprendizagem colaborativa. Alarcão \& Tavares (2010, p. 121) referem que

os professores, como adultos, não aprendem tanto com a frequência de cursos ou a leitura de livros e revistas, mas sobretudo com a observação, análise e reflexão do seu próprio ensino ou do ensino praticado pelos seus colegas.

Ora, este estudo sustenta que uma postura de controlo na avaliação do desempenho profissional tem mais efeitos perversos do que efeitos positivos sobre a qualidade do ensino de um docente e o seu desenvolvimento profissional, tal como defendem vários autores, Alves \& Machado (2010), Lison \& De Ketele (2007).

A interação entre pares promove a criação de redes de aprendizagem profissional, porque emula bem a aprendizagem colaborativa (Rhodes, Stokes \& Hampton, 2004). E, Flores \& Simão (2009) salientam o facto de cada docente poder gerir e controlar a sua agenda de necessidades, encaixando-a num empreendimento conjunto. As redes de aprendizagem dão aos docentes a possibilidade de refletir conjuntamente sobre os aspetos relacionados com o seu trabalho, para aprenderem uns com os outros e discutirem questões curriculares, entre outras (Henriques, 2010).

O conhecimento profissional, segundo Roldão (2010), é o resultado de um conjunto de fatores, entre eles a prática reflexiva, que contribui para o desempenho adequado da ação de ensinar, de repensar e teorizar essa ação, aumentando a cultura profissional, que, por sua vez, em oposição à rotina, desenvolve nos profissionais da educação a capacidade analítica, assente no questionamento constante e interpretativo, que sustenta a ideia de "comunidade de professores aprendentes".

Assim, a interação entre pares é uma abordagem que pode melhorar o desempenho docente, porque ativa a regulação cognitiva dos implicados através das atividades de planeamento de estratégias, de monitorização e avaliação, e de resolução de problemas. Em termos de "como a regulação da cognição pode melhorar a aprendizagem, a investigação indica que é importante uma melhor apreciação das lacunas na compreensão" (Sá, 2015, p. 50).

Corroborando esta perspetiva, Leite \& Fernandes (2010, p. 199), num contexto holístico, enfatizam que

em Portugal, este trabalho pedagógico e curricular para que os professores têm vindo a ser chamados aponta para que seja realizado com o grupo de pares - não só os professores das turmas com quem trabalham, mas com todos os professores da escola - num registo que se deseja de partilha e de construção colectiva. 


\section{Metodologia}

O principal objetivo desta investigação, de natureza qualitativa, com dados não numéricos e não estruturados, usando o método estudo de caso, é analisar as potencialidades do trabalho colaborativo entre pares, recorrendo à realização de narrativas e à reflexão sobre as mesmas, e a entrevistas semiestruturadas, para esclarecer algum ponto/aspeto do estudo.

No âmbito deste estudo, os Diários são determinantes enquanto documentos de registo, reflexão e análise. Assim, solicitou-se a três docentes de Ciências Físico-Químicas, de uma escola com $3^{\circ}$ ciclo do ensino básico da região norte de Portugal, que escrevessem Diários, registando passo a passo todo o processo do trabalho colaborativo implicado pelo seu trabalho docente. As três docentes lecionavam o mesmo nível de escolaridade, o $8^{\circ}$ ano, posicionadas no $7^{\circ}$ escalão, que corresponde, em média, a 32 anos de serviço letivo. Este estudo teve a permissão da Direção do agrupamento de escolas, em resposta à carta enviada pela autora. Sugeriu-se às docentes que adotassem um modo de registo simples que refletisse o essencial dos diálogos estabelecidos entre elas e com os alunos. Deste modo, os Diários incidiram sobre a identificação de problemas, definição de objetivos e estratégias de resolução, registo da preparação de aulas laboratoriais, planificação de aulas e reflexão sobre a ação, durante um período letivo de cerca de 3 meses.

A produção destes documentos serviu para as docentes descreverem as situações vividas e refletirem sobre o processo e, para a autora deste estudo, para monitorizar o próprio projeto de trabalho colaborativo interpares. As entrevistas semiestruturadas foram individuais, decorreram na escola, numa sala disponibilizada pelas docentes e tiveram a duração de cerca de uma hora, cada.

Nesta investigação, após a transcrição das entrevistas e análise de conteúdo das entrevistas e das três narrativas correspondentes aos Diários das docentes, procedeu-se à leitura flutuante. Deste modo, as ideias foram sendo recortadas em unidades de registo, palavras ou frases, pedaços de texto constantes do material informativo produzido, que correspondiam a ideias claras, objetivas e com significado no contexto da investigação. Após a realização de uma leitura em profundidade, as unidades de registo foram agrupadas em indicadores e foram estabelecidas subcategorias que, mais tarde, permitiram clarificar a definição de cada uma das dimensões. Como unidade de frequência, tomou-se a unidade de registo ou de referência, a qual foi contabilizada tantas vezes quantas as que aparecia no discurso das participantes.

Para garantir a validação ou credibilidade (Amado, 2013) da investigação qualitativa e de acordo com alguns autores, Stake (2007) e Yin (2009), houve necessidade de estabelecer a triangulação entre as narrativas e as entrevistas. De qualquer modo, 
e ainda neste sentido, tornar-se-á tão claro quanto possível o encadeamento das evidências, tal como defendem Neri de Souza, Pedro Costa \& Neri de Souza (2015).

No tratamento e na técnica de análise de dados, recorreu-se à análise de conteúdo, com a exploração de texto introduzido no software webQDA (Souza, Costa \& Moreira, 2011). Os dados foram sujeitos a codificação de nós em árvore e o questionamento dos dados foi permanente com a triangulação entre as narrativas e as entrevistas.

O estudo contemplava três dimensões: a avaliação, a liderança e a aprendizagem. Neste artigo, apenas se apresentam os dados relativos à dimensão, "Aprendizagem do aluno", representados na tabela 1 (Sá \& Costa, 2016, p. 407).

Tabela 1. Subcategorias e Indicadores relativos à Dimensão, "Aprendizagem do aluno"

\begin{tabular}{|l|l|}
\hline \multicolumn{1}{|c|}{ Subcategorias } & \multicolumn{1}{c|}{ Indicadores } \\
\hline Planificação & Trabalho colaborativo \\
\hline Alterações à planificação & Justificação das alterações \\
\hline Reflexão & $\begin{array}{l}\text { Fatores que favoreçam a } \\
\text { aprendizagem do aluno }\end{array}$ \\
\hline Partilha de tarefas & Otimização do trabalho docente \\
\hline Resolução de problemas & Melhorias na sala de aula \\
\hline Aperfeiçoamento profissional & Feedback constante \\
\hline Autonomia docente & Melhoria de sala de aula \\
\hline Horário docente & Favoreça o trabalho colaborativo \\
\hline Avaliação dos alunos & Realização de avaliações comuns \\
\hline Recursos docentes & Impacto na aprendizagem dos alunos \\
\hline Avaliação de desempenho docente & $\begin{array}{l}\text { Implica mudança de atitudes na sala } \\
\text { de aula }\end{array}$ \\
\hline
\end{tabular}

Definindo as subcategorias emergentes dos dados: na subcategoria, "Planificação", incluem-se todas as respostas que referiam que as planificações das metas curriculares, a longo e a curto prazo, foram elaboradas de modo colaborativo; na subcategoria, "Alterações à planificação", agrupam-se as que referiam alterações à planificação, desde que justificadas; à subcategoria, "Reflexão", atribuem-se as que envolvem reflexão sobre o contexto, processos e sistemas, dentro do trabalho colaborativo, que possam identificar fatores que favoreçam a aprendizagem do aluno; à subcategoria, "Partilha de tarefas", quando se constatou a repartição de tarefas entre os pares com vista à otimização do trabalho docente; à subcategoria, "Resolução de Problemas", quando as respostas apontavam para a assunção individual de responsabilidade na resolução de dilemas e constrangimentos dentro da escola, para que o desenvolvimento profissional possa ser traduzido em melhorias na sala de aula; à subcategoria, "Aperfeiçoamento profissional", quando as respostas englobavam o trabalho colaborativo entre pares e recorre ao feedback constante, a fim de o aperfeiçoamento profissional permitir identificar as necessidades dos professores para fornecer 
conhecimentos (palestras, seminários, etc.) e recursos; à subcategoria, "Autonomia Docente", quando os pares respondiam que são suficientemente autónomos e nada constrangidos para tomar decisões e/ou ações para que o desenvolvimento profissional possa ser traduzido numa melhoria na sala de aula; à subcategoria, "Horário docente", quando referiam existir nos horários dos colegas horas simultâneas que permitam implementar, incorporar e avaliar mudanças na prática, que possam ter impacto sobre a aprendizagem; à subcategoria, "Avaliação dos alunos", quando o questionário para a avaliação periódica dos alunos era construído com matrizes comuns, permitindo a realização de testes sumativos com idêntico grau de dificuldade; à subcategoria, "Recursos docentes", quando as respostas indicavam que foram produzidos recursos necessários que facilitaram a prática docente e com impacto na aprendizagem do aluno; à subcategoria, "Avaliação de desempenho docente", quando as respostas indicavam que a avaliação do desempenho docente se relaciona com a satisfação dos participantes ou com mudanças na prática ou impacto sobre a aprendizagem do aluno.

\section{Resultados}

Apresentam-se e discutem-se, de seguida, os dados obtidos a partir da triangulação entre o conteúdo das três narrativas (que iremos referir com a letra N) e das três entrevistas (que iremos referir com a letra E), relativamente à dimensão, "Aprendizagem do aluno".

A homogeneidade da categorização resulta da homogeneidade da fonte de documentos, pois as narrativas são resultantes dos diários dos interlocutores, e as entrevistas são testemunhos orais, resultantes da interpretação pessoal dos entrevistados sobre o objeto em questão, pelo que a categorização resultou, sobretudo, de dados emergentes da transcrição das entrevistas. A análise desta variedade de fontes de dados foi organizada e sistematizada por meio de uma árvore de categorias (dimensão), permitindo à investigadora registar todo o contexto da investigação, questionar os dados e classificar relações (Neri de Souza, Pedro Costa \& Neri de Souza, 2015). Assim, de modo a organizar e clarificar a apresentação dos resultados e demonstrar a coerência interna da investigação, faz-se a análise das entrevistas e das narrativas por objetivos de investigação, seguida de discussão e de uma síntese para aglutinar e destacar os resultados essenciais, tentando dar resposta às perguntas de investigação. A validade e a confiabilidade dos procedimentos da investigação qualitativa pode ser efetuada através da tabela de Coerência Interna Geral da Investigação, onde constam a questão da investigação, o objetivo da investigação, o corpus de dados, tipos de análise, observações e expectativas. Deste modo, o investigador "alcança uma maior veracidade e coerência na investigação" (Neri de Souza, Pedro Costa \& Neri de Souza, 2015, p. 152), tal como se mostra na tabela 2 (Sá \& Costa, 2016, p. 408). 
Tabela 2. Coerência interna da investigação para a Dimensão, "Aprendizagem do aluno"

\begin{tabular}{|c|c|c|c|c|}
\hline $\begin{array}{l}\text { Questão de } \\
\text { investigação }\end{array}$ & $\begin{array}{l}\text { Objetivo de } \\
\text { investigação }\end{array}$ & $\begin{array}{l}\begin{array}{l}\text { Corpus } \\
\text { dados }\end{array} \\
\end{array}$ & $\begin{array}{ll}\text { Tipos } & \text { de } \\
\text { Análise } & \\
\end{array}$ & $\begin{array}{l}\text { Observações } \\
\text { Expectativas }\end{array}$ \\
\hline $\begin{array}{l}\text { A interação } \\
\text { entre pares } \\
\text { favorece as } \\
\text { aprendizagens } \\
\text { dos alunos e o } \\
\text { desenvolvimento } \\
\text { profissional dos } \\
\text { docentes? }\end{array}$ & $\begin{array}{l}\text { Analisar as } \\
\text { potencialidades } \\
\text { do trabalho } \\
\text { colaborativo } \\
\text { entre pares }\end{array}$ & $\begin{array}{l}\text { Narrativas dos } \\
\text { diários de aulas } \\
\begin{array}{l}\text { Entrevistas às } \\
\text { docentes }\end{array}\end{array}$ & $\begin{array}{ll}\text { Análise } & \text { de } \\
\text { Conteúdo } & \\
\text { Análise } & \\
\text { Documental } & \end{array}$ & $\begin{array}{l}\text { Esperamos } \\
\text { poder comparar } \\
\text { os dados das } \\
\text { entrevistas dos } \\
\text { docentes e } \\
\text { correlacioná-los } \\
\text { com narrativas dos } \\
\text { diários de aulas }\end{array}$ \\
\hline
\end{tabular}

Selecionou-se a dimensão, "Aprendizagem do aluno", porque do questionamento dos dados relativamente às palavras mais frequentes se destaca a palavra "Aprendizagem", tal como pode constatar-se na tabela 3.

Tabela 3. Palavras mais frequentes

\begin{tabular}{|c|c|}
\hline Palavras Frequentes & Frequência \\
\hline Aprendizagem & 197 \\
\hline Aluno & 190 \\
\hline Colaborativamente/Colaborativo & 105 \\
\hline Estratégias & 97 \\
\hline Aula & 51 \\
\hline
\end{tabular}

Ao longo da discussão dos resultados, utiliza-se o termo unidade de referência como unidade de registo, que pode ser a frase ou conjunto de palavras que façam sentido e tenham significado.

Apresenta-se, na tabela 4, a matriz resultante das unidades de referência dos vários indicadores na triangulação nas narrativas e nas entrevistas respeitante à dimensão, "Aprendizagem do aluno" (Sá \& Costa, 2016, p. 409). 
Tabela 4. Matriz da Dimensão, "Aprendizagem do aluno"

\begin{tabular}{|l|c|c|}
\hline \multicolumn{1}{|c|}{ Indicadores } & $\begin{array}{c}\text { Narrativas } \\
\text { (unidades de } \\
\text { referência) }\end{array}$ & $\begin{array}{c}\text { Entrevistas } \\
\text { (unidades de } \\
\text { referência) }\end{array}$ \\
\hline Trabalho colaborativo & 31 & 8 \\
\hline $\begin{array}{l}\text { Justificação das } \\
\text { alteraços }\end{array}$ & 5 & 2 \\
\hline $\begin{array}{l}\text { Fatores que favoreçam } \\
\text { aprendizagem do } \\
\text { aluno }\end{array}$ & 25 & 4 \\
\hline $\begin{array}{l}\text { Em vista à otimização } \\
\text { do trabalho docente }\end{array}$ & 12 & 11 \\
\hline $\begin{array}{l}\text { Em vista a melhorias na } \\
\text { sala de aula }\end{array}$ & 36 & 11 \\
\hline Feedback constante & 25 & 12 \\
\hline $\begin{array}{l}\text { Melhoria de sala de } \\
\text { aula de }\end{array}$ & 12 & 5 \\
\hline $\begin{array}{l}\text { Favorece o trabalho } \\
\text { colaborativo }\end{array}$ & 37 & 13 \\
\hline $\begin{array}{l}\text { Realização } \\
\text { avaliações comuns }\end{array}$ & 7 & 0 \\
\hline $\begin{array}{l}\text { Impacto } \\
\text { aprendizagem dos } \\
\text { alunos }\end{array}$ & 38 & \\
\hline $\begin{array}{l}\text { Implica mudança de } \\
\text { atitudes na sala de aula }\end{array}$ & 4 & \\
\hline
\end{tabular}

Pela análise da tabela 4, verifica-se que as docentes são unânimes quanto à existência sistemática de interação entre pares apenas se a liderança apoiar ativamente o trabalho colaborativo, uma vez que a maioria das respostas referia existirem nos horários dos colegas horas simultâneas que permitem implementar, incorporar e avaliar mudanças na prática que possam ter impacto sobre a aprendizagem (37 unidades de referências nas narrativas e 12 nas entrevistas): "isto só foi possível porque temos aquela hora em que as três temos furo"(E); "É muito importante os docentes que lecionam o mesmo nível de ensino terem contemplado no seu horário horas comuns para poderem trabalhar colaborativamente"(E); "Aguardei o momento em que nos reuníamos semanalmente para colocar a questão da problemática de indefinição de linguagem densidade relativa, massa volúmica ou densidade como está no manual dos alunos"(N). As docentes produziram uma planificação em "trabalho colaborativo" (31 unidades de referências nas narrativas e 8 nas entrevistas): "trabalhamos a planificação em função da nossa maneira de lecionar na sala de aula" (E), e "Planificamos as três"(N); "Rever a nossa planificação"(N). 
No indicador, "justificação das alterações", verificam-se 5 unidades de referência nas narrativas e 2 nas entrevistas: "na nota que anexamos no subdomínio 1.13 (nomenclatura dos iões) do domínio Explicação e representação de reações químicas, da planificação a curto prazo"(N); "acrescentávamos notas e alterações à planificação, sempre que o justificasse."(E).

Na subcategoria, "Recursos docentes", registaram-se 38 unidades de referências nas narrativas e 13 nas entrevistas: "fizemos fichas de trabalho que ajudaram a consolidar os conhecimentos dos nossos alunos" (E); "a ficha 3 foi adaptada tendo em vista o meu aluno $X$ e a aluna $Y$ da colega $A$ " $(\mathrm{N})$; "a abordagem à massa volúmica resultou muito melhor com o ppt que preparamos do que a explicação que têm no manual" $(\mathrm{N})$; "com esta ficha as aprendizagens foram mais bem consolidadas no subdomínio 1.2"(N); "tive que alterar a minha estratégia habitual, decidi escrever o sumário no final da aula, para controlar melhor a turma desde o início, foi uma boa sugestão das colegas" $(\mathrm{N})$; "realizei muito mais trabalho laboratorial, sem medo, porque os alunos tinham um guião para preencher que realizamos no grupo"(N).

Relativamente ao indicador, "Fatores que favoreçam a aprendizagem do aluno", registam-se 25 unidades de referência nas narrativas e 4 nas entrevistas, o que demonstra que as docentes refletiram sobre o contexto, processos e sistemas dentro do trabalho colaborativo, e identificaram fatores que favorecem a aprendizagem do aluno: "O aluno $\mathrm{X}$ está desinteressado, vou levar esta situação à reunião das colegas para pedir opinião"(N); "muitas vezes discutíamos estratégias para resolver problemas de indisciplina na nossa sala de aula e parecia que não estávamos tão sós"(E); "hoje foi uma vitória para mim, o X começou a interessar-se pela disciplina, estou mortinha para contar às minhas colegas que a estratégia de solicitar, antes de $15 \mathrm{~min}$, do final da aula, a resposta a 3 ou 4 quiz, ao fim de 3 semanas, resultou, o grupo desmotivado começou a ter curiosidade e a mostrar interesse na aula para poder responder ao quiz."(N).

Focando a subcategoria, "Aperfeiçoamento profissional", as respostas com 25 unidades de referência nas narrativas e 11 nas entrevistas: "Foi útil o seminário sobre a utilização da máquina de calcular NSpire da Texas" (N); "Tive de ir junto da direção, mais do que uma vez, solicitar verbas para a aquisição de reagentes para podermos realizar 2 atividades laboratoriais obrigatórias"(N); "um exemplo que me marcou foi, como é que com uma simples máquina de calcular podemos entusiasmar os alunos com o quadro interativo, que nem eu sabia usar"(N); "uma coisa interessante foi ter formação naquilo que nós efetivamente precisávamos e não frequentar ações de formação só para obter créditos e que para a nossa vida profissional não têm interesse"(E).

Na subcategoria, "Partilha de tarefas", verificam-se 12 unidades de referência nas narrativas e 9 nas entrevistas: "dividíamos as tarefas pelas três" $(\mathrm{N})$; "as tarefas de preparação de atividades laboratoriais era sempre para a colega B porque sempre 
se sentiu mais à vontade nesta área, e assim ajudou-me muito porque eu era muito complexada, achava que os alunos se distraíam muito nas aulas laboratoriais"(E); "Eu aprendi a fazer fichas de trabalho para realizar em grupo, a colega $A$ ensinou-me, eu tinha receio de realizar trabalhos de grupo porque os alunos se distraíam, mas tudo depende do modo como o construímos"(E).

Relativamente ao indicador, "Em vista a melhorias na sala de aula", na subcategoria "Aperfeiçoamento profissional", obtiveram-se 36 unidades de referência nas narrativas e 11 nas entrevistas, como exemplos, "aprecio o trabalho com as colegas porque na reunião que temos têm sempre o cuidado de me perguntar como é que resultou a estratégia na minha turma, ou a ficha, etc., porque tenho a turma mais complicada a nível comportamental"(N); "Às vezes discutíamos entre as três, mas da discussão fazia-se luz. Essa discussão era saudável, não significava que estivéssemos sempre de acordo e nos anulássemos enquanto pessoas"(E); "Senti-me sempre acompanhada com este tipo de trabalho, porque todas me perguntavam se tudo estava a correr bem e eu notava a partir da reação positiva dos alunos"(E); "Trabalhar assim, sem medos de nos expormos, mesmo cientificamente, é bom, porque ajudamo-nos mutuamente, verdadeiramente" $(\mathrm{N})$.

Na subcategoria, "Autonomia Docente", obtiveram-se 12 unidades de referência nas narrativas e 4 nas entrevistas: "Se eu achasse que aquele método funcionava melhor com o tipo de aluno que tinha, eu ia por aí, mesmo que as minhas colegas não concordassem." (E); "apesar de as minhas colegas acharem que a ficha 3 do manual era ótima para se trabalhar o subdomínio 2.1 na sala de aula, eu optei por fazer uma ficha diferente." $(\mathrm{N})$; "Uma coisa que sempre se notou foi que ninguém impôs nada a ninguém, apenas se dava sugestões, mas cada uma de nós é que conhecia a realidade da sua sala de aula e é que sabia o que iria funcionar melhor"(E).

Na subcategoria, "Avaliação dos alunos", encontram-se 7 unidades de referência nas narrativas e 5 nas entrevistas, tendo como exemplos: "uma coisa ótima era que dávamos o mesmo teste a todos os alunos à mesma hora e corrigíamos partes dos testes umas das outras" (N); "as reuniões de avaliação deixaram de ser uma dor de cabeça, porque vou mais segura atribuir as classificações, porque sei que o meu 3 é igual a um 3 de um outro aluno de uma outra turma, do mesmo ano letivo, da mesma escola, mas de professor diferente"(N); "com o nosso método de avaliação sumativo, há maior equidade entre os alunos das diferentes turmas do mesmo nível de ensino"(E).

Itimo debruçaremos sobre a subcategoria alunos e, sobretudo, utilizar o quadro interativo que a maioria dos professores diz que"Por último, a subcategoria, "Avaliação de desempenho docente", obtiveram-se apenas 4 unidades de referência relativas às narrativas: "Sei que este diário vai servir para ser avaliada, mas não me preocupa, escrevi o que achava que devia escrever, fui sincera, porque gostei da experiência, trabaIhei muito e isso foi positivo para os meus alunos"(N); "sinceramente, acho que assim, 
para esta folha, consigo dizer tudo o que penso, e trabalhei muito, mas com prazer, sem medo, à vontade. Aprendi muito" $(\mathrm{N})$; "sempre fui de opinião de que em grupo se trabalha melhor do que sozinho. Os resultados estão à vista. Produzimos bastantes materiais. Houve bastante sucesso escolar e eu estou muito satisfeita com a experiência e com os resultados obtidos"(N); "Trabalhei muito, aprendi muito, modifiquei as minhas metodologias na sala de aula, cresci muito em termos profissionais. Hoje sou uma professora melhor"(N). A questão colocada na entrevista referente a esta subcategoria, "Alterou as suas práticas pedagógicas na sala de aula?", teve respostas idênticas: "eu não perdi a minha identidade, pelo facto de trabalhar com as colegas"(E), "Eu continuo a ser a mesma professora de sempre" (E). Nas entrevistas, estas mudanças de atitude ou de hábitos não transpareciam, pois parece que as docentes receavam verbalizar perante estranhos os seus medos e as suas limitações, apesar de, como resultado do trabalho colaborativo, se terem efetuado mudanças, enquanto profissionais, tal como se tornaram visíveis nos seus diários.

Analisando as respostas das docentes por indicador, gráfico 1, pode-se verificar que são similares, à exceção dos indicadores "trabalho colaborativo" e "melhorias da sala de aula".

Gráfico 1: Distribuição das unidades de referência de resposta das docentes por indicador.

\section{DISTRIBUIÇÃO DAS REFERÊNCIAS POR DOCENTE}

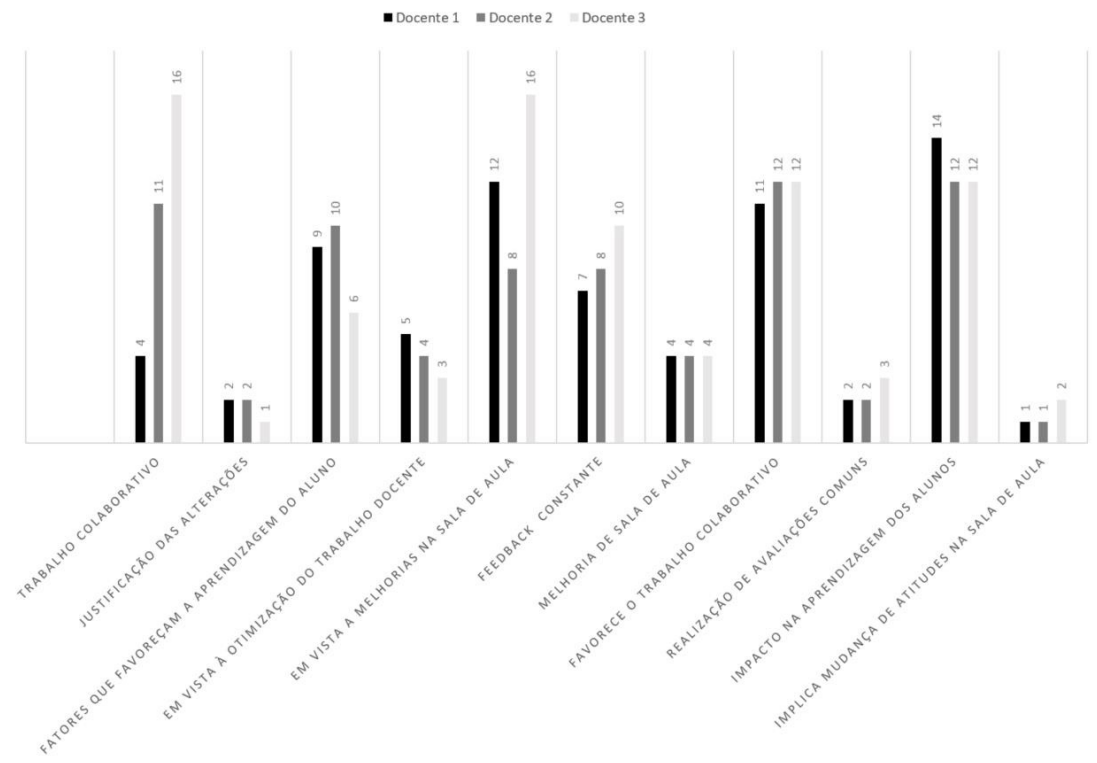


Ora, relativamente ao trabalho colaborativo, esta diferença pode explicar-se a partir da dinâmica de grupo, onde espontaneamente se destaca um membro com perfil de líder. A Docente 1 adotou esse perfil e a Docente 3 era a mais "fragilizada", a que dizia sentir-se com mais receios e medos, como reforça uma expressão da sua narrativa, "acho-me velha" $(\mathrm{N})$. Assim, talvez a Docente 1 não dê tanta ênfase à planificação como modo de colaboração, embora a tenha realizado e sentido, tal como explicita na entrevista, "Fazermos ajustes em comum na planificação foi uma mais-valia"(E), enquanto que em "melhorias de sala de aula", se verifica que afinal não é assim tão autónoma do grupo. Relativamente à Docente 3, a fragilidade fica espelhada no indicador "melhoria de sala de aula" em que esta docente foi a que mais se sentiu beneficiar do trabalho colaborativo, pois "as colegas ajudaram-me imenso, afinal fazer aulas laboratoriais não é nenhum bicho de sete cabeças”(E).

\section{Considerações Finais}

Nas condições do caso descrito, a interação entre pares teve efeitos positivos sobre a qualidade do ensino, porque favoreceu a construção e partilha, pelas docentes, de melhores recursos didáticos, e o aprofundamento de conteúdos de ensino, com adaptações mais tempestivas destes às condições de aprendizagem, através do uso de feedback e do trabalho colaborativo. Assim, promoveu, simultaneamente, o desenvolvimento profissional das docentes implicadas, em função das suas lacunas e necessidades e a melhoria da aprendizagem dos estudantes, pela descoberta, em tempo, das suas dificuldades.

Pelo modo de interação entre pares, as competências das docentes foram empenhadas na realização de objetivos centrais em condições de regulação, de autorregulação e de superação da rotina, pela atitude de abertura a inovações integradas no quotidiano da sala de aula.

Que as relações pessoais e profissionais entre colegas, no contexto de interação entre pares, contribuíram para o desenvolvimento profissional é corroborado pelas respostas dos indicadores, "Partilha de tarefas" e "Aperfeiçoamento profissional".

As relações de confiança e o debate gerado pela interação entre pares potenciam mais a qualidade do processo de ensino e de aprendizagem, pela possibilidade de resolver problemas de imediato e de desencadear mudanças na prática letiva, do que é expectável que ocorra com o uso de controlo pelo modelo de supervisão entre pares, dirigido por um estranho, só para algumas parcelas da atividade do docente supervisionado, e apenas durante alguns tempos letivos. A ocorrer alguma mudança positiva no contexto, no processo e nos resultados, provocada pela supervisão acima descrita, ela só ocorrerá a partir do ano letivo seguinte. 
A discussão franca e honesta entre as três docentes permitiu a aferição de metodologias e estratégias de ensino-aprendizagem-avaliação, relativamente à subcategoria, "Avaliação dos alunos", contribuindo, por essa via, para o sucesso educativo dos estudantes.

A redação de narrativas, por parte das docentes, potenciou a sua reflexão e ação, já que o ato de escrita foi realizado a posteriori.

A entrevistadora, embora conhecida das docentes, não deixou de Ihes desencadear, involuntariamente, alguma ansiedade durante a entrevista, podendo simular o resultado de um ato de supervisão do desempenho docente, que, como tal, produziria interferências que mascarariam os resultados.

O trabalho realizado no decorrer desta investigação levou as docentes a desenvolver processos de reflexão, nunca experienciados até à data, os quais Ihes permitiram um olhar mais crítico e analítico das suas prestações profissionais, de forma a procurar melhorar o seu desempenho e o consequente desempenho dos seus alunos.

Desta investigação, pode-se retirar implicações para o desenvolvimento profissional e pessoal do docente, relacionadas essencialmente com o papel da interação entre pares, a relevância da prática colaborativa dentro das escolas e a importância da reflexividade na prática docente, pois todas contribuem para a construção de aprendizagens mais eficazes, visto que a cooperação, com o propósito comum da melhoria da qualidade do ensino e, consequentemente, das aprendizagens dos alunos, deixa-os mais enriquecidos, tal como advogam vários autores (Formosinho, 2002; Trindade, 2007; Ribeiro, 2012; Leite \& Fernandes, 2010; Sá, 2015; Sá \& Costa, 2916). Servindo para o desenvolvimento profissional do docente, será uma alternativa para a avaliação de desempenho docente.

Deste trabalho de investigação, do qual se apresenta a análise de uma só dimensão, resultou uma grelha para avaliação do trabalho colaborativo entre pares para diferentes departamentos escolares, a ser preenchida pelos coordenadores e/ou avaliadores, em uso numa escola secundária de um agrupamento de escolas do norte de Portugal.

\section{Referências Bibliográficas}

Alarcão, I. \& Roldão, M. (2008). Supervisão: um contexto de desenvolvimento profissional dos professores. Mangualde: Pedago.

Alarcão, I. \& Tavares, J. (2010). Supervisão da prática pedagógica: uma perspectiva de desenvolvimento e aprendizagem. Coleção Ciências da Educação e Pedagogia. Coimbra: Almedina.

Alves, P. \& Machado, A. (2010). O Pólo de Excelência: Caminhos para a Avaliação do Desempenho Docente. Porto: Areal Editores. 
Amado, J. (2013). Manual de Investigação Qualitativa em Educação. Coimbra: Imprensa da Universidade de Coimbra.

Damas, M. \& De Ketele, J. (1985). Observar para Avaliar. Coimbra: Livraria Almedina.

Decreto-Lei na 26/2012. (s.d.). Diário da República, 1.a série - No 37-21 de fevereiro de 2012. Lisboa: Ministério da Educação, consultado em 10 de fevereiro, http://projectos.braga.ucp.pt/docs/ DR_26_2012_ADD.pdf.

Flores, M. \& Veiga Simão, A. (2009). Aprendizagem e desenvolvimento profissional de professores: contextos e perspectivas. Coleção Educação e Formação. Mangualde: Edições Pedago.

Formosinho, J. (2002). A Supervisão na Formação de Professores II. Da Organização à Pessoa. Porto: Porto Editora.

Freitas, F. Costa, A. \& Neri de Souza, F. (2016). Teachers' perception of WEBMAT platform. Revista Lusófona de Educação, 33, 161-177. Consultado em 5688-397-17970-1-10-20161205.pdf.

Henriques, M. (2010). Supervisão inter-pares: Um percurso colaborativo de formação. Dissertação de mestrado não publicada, Lisboa: Instituto Politécnico de Lisboa.

Lison, Ch. \& De Ketele, J. (2007). De la satisfaction au moral professionnel des enseignants. Étude de quelques déterminants. Revue des Sciences de l'Education, 43, 141-157.

Leite, C. \& Fernandes, P. (2010). Desafios aos professores na construção de mudanças educacionais e curriculares: que possibilidades e que constrangimentos? Educação, Porto Alegre, 33(3), 198-204. Consultado em 10/02/2016 em www.revistaseletronicas.pucrs.br.

Rhodes, C., Stokes, M. \& Hampton, G. (2004). A Practical Guide to Mentoring, Coaching and Peer. Networking: teacher professional development in schools and colleges. London: RoutledgeFalmer.

Ribeiro, F. (2012). Supervisão entre pares: Contributos para a Melhoria das Práticas de Ensino. Dissertação de mestrado não publicada, Porto: Universidade Portucalense.

Roldão, M. (2010). Construção de planos individuais de trabalho e desenvolvimento profissional. Coleção Situações de Formação, n.1. Aveiro: Universidade de Aveiro.

Sá, S. (2015). Ensino, Aprendizagem e Avaliação no Ensino Superior: Perspetivas e Práticas. Tese de doutoramento não publicada, Braga: Universidade do Minho.

Sá, S. \& Costa, A. (2016). Interação Entre Pares: Uma Alternativa para a Avaliação do Desempenho Docente. In A. Costa, P. Castro, S. Sá, J. Carvalho, F. Neri de Souza \& D. Neri de Souza (Eds.). Atas do $5^{\circ}$ Congresso de Análise Qualitativa (pp. 403-412). Porto: Universidade Lusófona.

Souza, N. de, Costa, A. P., Moreira, A. (2011). webQDA. Aveiro: Centro de Investigação Didática e Tecnologia na Formação de Formadores da Universidade de Aveiro e Esfera Crítica, Consultado em www.webqda.com.

Stake, R. (2007). A arte da investigação com estudo de caso. Lisboa: Fundação Calouste Gulbenkian.

Trindade, V. (2007). Práticas de Formação. Métodos e Técnicas de Observação, Orientação e Avaliação (em Supervisão). Lisboa: Universidade Aberta.

Yin, R. (2009). Case Study Research: Design and Methods. (4 th Ed.). Vol. 5. London: Sage. 
Sá: A Interação entre pares: que lugar na avaliação do desempenho docente?

Susana Oliveira Sá

Agrupamento de Escolas Carlos Amarante, Braga, Portugal, Investigadora do Centro de Investigação em Estudos da Criança (CIEC), Universidade do Minho, Braga, Portugal susanaemiliasa@gmail.com

Correspondência Susana Oliveira Sá

Universidade do Minho, Centro de Investigação em Estudos da Criança

R. da Universidade, 4710-057 Braga

Data de submissão: Julho 2016

Data de avaliação: Outubro 2016 Data de publicação: Setembro 2017 